\title{
On the health risks of "hidden poisons on our table", good agricultural practices, pesticide residues in food, and dietary exposure assessments
}

\author{
Sobre os riscos para a saúde dos "venenos \\ ocultos na nossa mesa", boas práticas agrícolas, \\ resíduos de pesticidas nos alimentos e avaliação \\ de exposição alimentar
}

\section{Sobre los riesgos de salud de "los venenos escondidos en nuestra mesa", buenas prácticas agrícolas, residuos de pesticidas en la comida y evaluación de la exposición dietética}

Francisco José Roma Paumgartten 1

doi: 10.1590/0102-311X00062221
Evidence-based risk management of pesticides is a complex multistep process that integrates Science, uncertainties, and social values to guide regulatory decision-making. Not surprisingly, concepts such as "acceptable daily intake" (ADI), "maximum residue limits" (MRL), and how ADI and MRL relates to each other, and to consumers health risks, are at times misinterpreted by those not involved in pesticide regulation.

In this regard, a CSP Editorial ${ }^{1}$ and one study 2 analyzing the Program for Analysis of Pesticide Residues in Food Products (PARA), from Brazilian Health Regulatory Agency (Anvisa), need some clarifications.

Food tolerance or MRL (highest tolerated food level expressed as $\mathrm{mg} / \mathrm{kg}$ ) is set by national regulatory authorities assuming that the crop was produced according to good agricultural practices. It considers experimental data on expected residues and toxicological reference values (ADI and ARfD - acute reference dose for chronic and acute exposures -, respectively). The set of MRL for a pesticide in different food products must be such as the active ingredient ADI (mg/kg-bwt/day) is not exceeded when the population consumes a diet containing a variety of foods. The contribution of each food for this basic diet (standard food basket) is also relevant for setting its MRL for a pesticide. The authors 2 (p. 3) state that "...the sum of an active ingredient MRL found in various cultures where the use is authorized cannot exceed its ADI" is a simplistic (and incorrect) interpretation of how MRLs derive from ADIs. As pointed out, the relative (quantitative) contribution of each and every food product within a national standard diet food basket is also considered to ensure that ADIs shall not be exceeded.

The crucial point here is that occasional violations of MRL values for specific foods do not necessarily imply that the pesticide ADI was exceeded. Dietary exposure assessments - investigations that combine food consumption data with information on pesticide residue levels in food - are necessary to inform regulators and public health scientists whether the current exposure levels exceed ADIs. If so, MRLs and/or authorized uses need revision to be compatible with ADIs.

According to Lopes \& Albuquerque 2 (p. 10), the procedure to establish ADIs is questionable because of the "weakness of the scientific evidence that support it", and procedures used to fix ADIs and MLRs would serve only to a "discourse of occultation" intended to strengthen the confidence on the tolerance limits. The authors' baseless and unfortunate allegations are at odds with the public health achievements provided by regulatory toxicology, and these allegations are unfair with the work of
1 Escola Nacional de Saúde Pública Sergio Arouca, Fundação Oswaldo Cruz, Rio de Janeiro, Brasil.

Correspondence F. J. R. Paumgartten Laboratório de Toxicologia Ambiental, Escola Nacional de Saúde Pública Sergio Arouca, Fundação Oswaldo Cruz. Av. Brasil 4036, Rio de Janeiro, $R J$ 21040-361, Brasil. paum@ensp.fiocruz.br 
worldwide renowned Joint World Health Organization (WHO)/UN Food and Agricultural organization (FAO) Meeting on Pesticide Residues (JMPR) and the Expert Committee on Food Additives and Contaminants (JECFA), whose independent experts set ADIs for pesticide/veterinary drug residues, and food additives and contaminants, respectively.

Lopes \& Albuquerque speculated that current ADIs are possibly flawed due to a concomitant exposure to several residues that might interact with each other synergistically. This hypothesis is unlikely and a 100 times or even greater safety factor is generally applied to the lowest reported "no observed adverse effect level" (NOAEL) when ADI is fixed. A synergism between constituents of complex mixtures of that order of magnitude is extremely unlikely. Along this line, Ito et al. 3 using rat multiorgan and hepatocarcinogenesis models showed that combined administration (for eight weeks) of 20 or 40 pesticide mixtures, each active ingredient at ADI or 100 times ADI levels, did not modulate carcinogenesis at any organ, thereby providing direct support for the use of a 100 times safety factor. A report on powerful synergism between pesticides in mixture was withdrawn amid a scientific integrity scandal 4.

Although FAO provides a set of Codex-MRLs, tolerance limits are established at national level. Trade problems may occur if tolerances differ between countries and thus a Codex-promoted international harmonization is desirable. However, regarding the consumer's health, what matters is whether ADIs and ARfDs are not exceeded. ADIs adopted by Anvisa and European Union are both consistent with those set by JPMR.

Finally, PARA data showed that, in a proportion of cases, farmers did not comply with good agricultural practices, a caveat for pesticide risk management and regulation. These data on noncompliance should guide interventions (agriculture authorities) aimed at strengthening good agricultural practices adherence. Dietary assessments of pesticide residues in food must be regularly performed to check whether ADIs are observed in Brazil.

\section{Conflict of interests}

The author declares no conflicts of interest.

\section{Additional information}

ORCID: Francisco José Roma Paumgartten (00000002-6207-0149).
1. Frota MTBA, Siqueira CE. Pesticides: the hidden poisons on our table. Cad Saúde Pública 2021; 37:e0004321

2 Lopes CVA, Albuquerque GSC. Desafios e avanços no controle de resíduos de agrotóxicos no Brasil: 15 anos do Programa de Análise de Resíduos de Agrotóxicos em Alimentos. Cad Saúde Pública 2021; 37:e00116219.

3. Ito N, Hagiwara A, Tamano S, Futacuchi M, Imaida K, Shirai T. Effects of pesticide mixtures at the acceptable daily intake levels on rat carcinogenesis. Food Chem Toxicol 1996; 34:1091-6.

4. McLachlan JA. Synergistic effect of environmental estrogens: report withdrawn. Science 1997; 277:459-63.

Submitted on 08/Mar/2021

Approved on 11/Mar/2021 